\title{
Three-Dimensional Pressure Modeling of South China Sea in High Temperature High Pressure Field
}

\author{
Aiqun Liu*, Peiyuan Zhu, Guangchao Pan, Caiwei Fan, Bing Liu, Yunpeng Wu \\ Zhanjiang Branch of China National Offshore Oil Corporation Ltd., Zhanjiang, China \\ Email: *liuaq@cnooc.com.cn
}

How to cite this paper: Liu, A.Q., Zhu, P.Y., Pan, G.C., Fan, C.W., Liu, B. and Wu, Y.P. (2017) Three-Dimensional Pressure Modeling of South China Sea in High Temperature High Pressure Field. Open Journal of Marine Science, 7, 271-280.

https://doi.org/10.4236/ojms.2017.72019

Received: March 3, 2017

Accepted: April 17, 2017

Published: April 20, 2017

Copyright ( 92017 by authors and Scientific Research Publishing Inc. This work is licensed under the Creative Commons Attribution International License (CC BY 4.0).

http://creativecommons.org/licenses/by/4.0/

\begin{abstract}
Yingqiong basin is a proven hydrocarbon-rich basin in South China Sea. There are a number of large exploration prospects in high temperature and over-pressured formations, especially in Yacheng Block of Qiongdongnan basin and Dongfang District of Yinggehai Basin. Owing to good exploration situation, we have already achieved proven geological reserves over $1000 \times 10^{8}$ $\mathrm{m}^{3}$. In recent years, a few drilled HPHT wells have confirmed that pressure predicted by conventional method was wildly inaccurate. From the view of regional stress, the accuracy of the pressure prediction will be substantially improved. Accurate pressure prediction and three-dimensional pressure modeling which are based on three-dimensional lithology modeling are the cornerstone to achieve exploration breakthrough. In this paper, the use of the triple constraint trend lithology model broke through the traditional method of seismic lithology prediction only by means of impedance threshold value. Compared with actual data and prediction, it confirms that three-dimensional pressure modeling method is reasonable and effective, and has a wide prospect of application.
\end{abstract}

\section{Keywords}

High Temperature and High Pressure Basin, Sedimentary Facies Model, Seismic Attribute Model, Lithology Model, Three-Dimensional Pressure Model, Pressure Prediction

\section{Introduction}

According to relevant references, more than two thirds of the world's sedimentary basins develop at different levels of overpressure, among which hydrocarbon distribution of about 160 sedimentary basins is closely genetically related 
with overpressure body. Large and medium-sized gas fields have been found in these overpressure basins, which indicates that overpressure is closely related to hydrocarbon generation, migration, accumulation and distribution and so on. Yinggehai-Qiongdongnan Cenozoic sedimentary basins were rapidly subsiding basins, which were characterized by abnormal high temperature and high pressure. Abnormal high pressure is mainly due to the late rapid subsidence and under-compaction mudstone formed by rapid deposition, which relies on steady subsidence and weak tectonic activity to maintain [1] [2] [3] [4] [5]. Different diapirs have various overpressure interfaces. Top interface of diapir zone in the central basin is generally $1500-2500 \mathrm{~m}$, while the southern part and the edge of non-diapirs zone generally have much deeper interfaces, which are significantly controlled by stratigraphy, lithology and boundary faults. Yinggehai and Huangliu formations are the main target strata with high pressure in Dongfang District, and a few drilled HPHT wells have confirmed that pressure predicted by conventional method was wildly inaccurate.

Over the years, old pressure prediction method leads to reservoir geologic evaluation problems and potential safety hazard, and even seriously restricts the HPHT exploration breakthrough in this field. The error of forecast will be reduced from the perspective of regional stress magnitude and direction. It's necessary to construct a three-dimensional pressure model mainly controlled by lithology model but the traditional forecasting method is only based on lithologic seismic impedance threshold value [6] [7] [8] [9]. Diapir area affected by lithology and fuzzy band, impedance of sandstone and mudstone is difficult to predict its vertical and horizontal distribution characteristics, so this research applies triple trend constraint method to construct lithology model in the deep layers of Dongfang district, which not only overcomes the disadvantages of the single impedance properties but also builds a high-precision lithologic model for the establishment of three-dimensional pressure model.

\section{Structural Model and Phase Model}

\subsection{Structural Model}

Structural model is the basis for the establishment of three-dimensional model, which reflects the formation of spatial framework and plays constrained role in phase model and property model. Structural model consists of interval model and fault model, which based mainly on structural surface owing to lack of faults. In the need of subsequent cap quality evaluation, mudstones can be divided into 4 layers based on structural interpretation of Huangliu formation. Flat grid spacing is set to $100 \mathrm{~m} * 100 \mathrm{~m}$ with 105 layers of vertical grid. Specific longitudinal layer is divided as follows: Four mudstones are successively divided into 20,10,10, 15 layers; the lower part of the reservoirs is divided into 50 layers with $2.2 \mathrm{~m}$ single average thickness.

\subsection{Phase Model}

During the first section of Huangliu formation (T30 - T31), the center of basin is 
conducive to the development of gravity flow. With transgression intensified, the scope of the deposition significantly expanded, the center of basin received a large reservoir system owing to surrounding active source system. Seismic facies have a transition from imbricate structure to chaotic characteristics, reflecting that the west of low delta directly connected to the submarine fan in the east. Main waterways have obviously undercut phenomenon in three-dimensional seismic profile, indicating rapid strong erosion with similar shape of submarine fan at home and abroad.

West of Dongfang a structure mainly developed delta front and fore-delta, up-leaning lithologic traps was formed by HST overlying mudstone and low fore-delta mudstone. During the first section of Huangliu formation, offshore beach and sand bars developed from Hainan provenance in the east. Inverted layered reservoir of III gas group in the thin edge of DFA well indicates hydrodynamic orientation. It's predicted that higher permeability reservoirs may be in higher parts and thicker sand dam body.

On the basis of sedimentary facies and its digital boundary [10] [11] [12], a deterministic sedimentary facies model will be established (Figure 1) as the restraint frame of lithology model and property model.

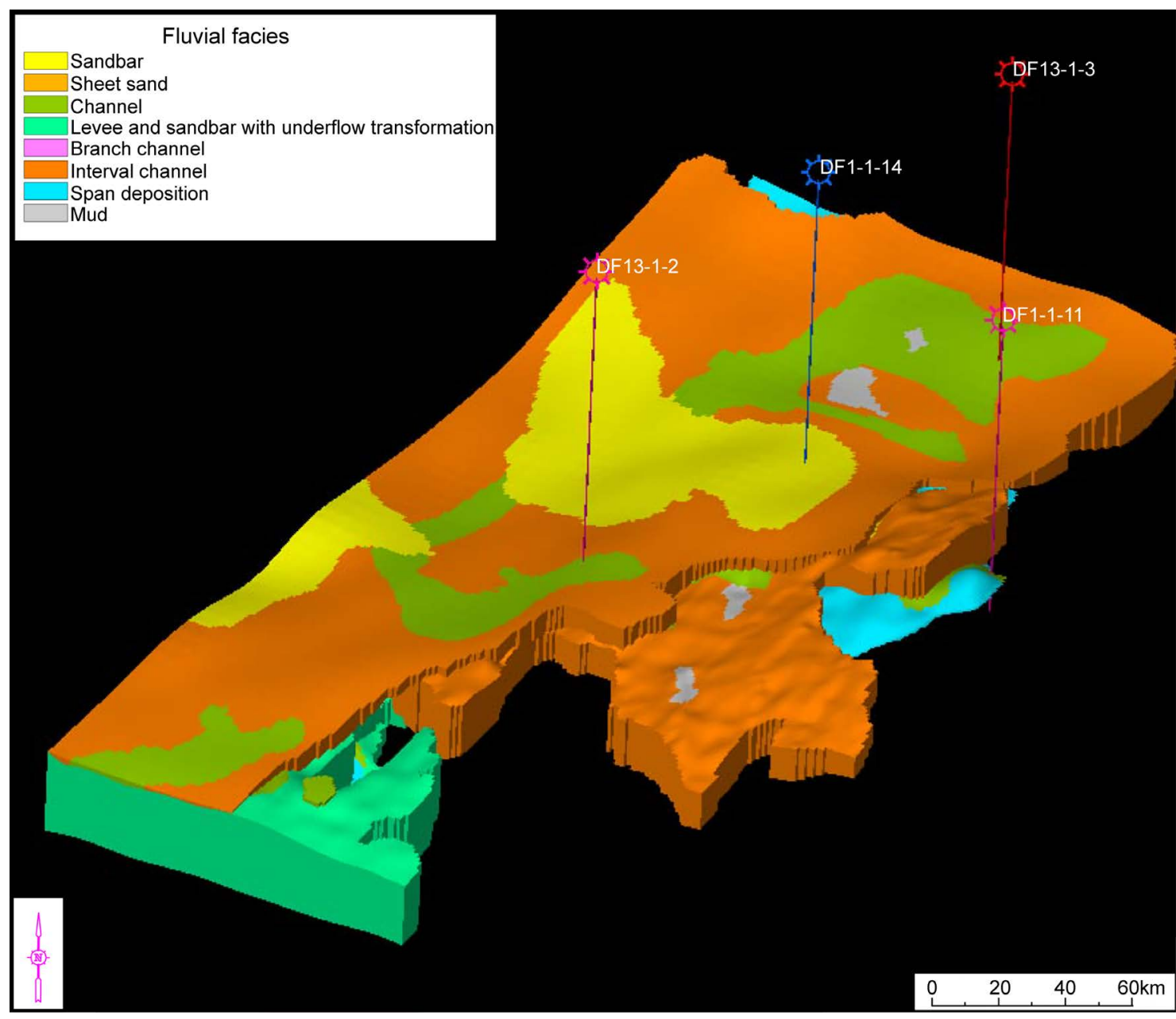

Figure 1. Sedimentary facies model of Dongfang area in Yinggehai basin. 


\section{Seismic Attribute Model}

A number of favorable geological modeling spatial prediction information can be obtained from seismic attribute data. Numerous seismic attributes are through the same seismic trace, but from different perspectives of understanding and interpretation. Multiplicity of seismic attributes can cause abnormal response owing to various fluids, reservoir properties and depositional environment. Combined with the actual drilling condition and sedimentary facies, conventional seismic attributes can better reflect sedimentary reservoir changes in the target area.

\subsection{Wave Impedance Model}

Petro-physical studied on four wells shows that: P-impedance properties can better distinguish between sandstone and mudstone. Mudstone shows high impedance, mainly concentrates in more than $8,000,000 \mathrm{~kg} / \mathrm{m}^{3} * \mathrm{~m} / \mathrm{s}$ region, while sandstone shows low impedance, the main concentrates in an area of less than $8,000,000 \mathrm{~kg} / \mathrm{m}^{3} * \mathrm{~m} / \mathrm{s}$. Therefore, wave impedance inversion can basically describe the variation between different wells. On the basis of the structural model, wave impedance inversion model will be obtained from wave impedance inversion results to grid model (Figure 2).

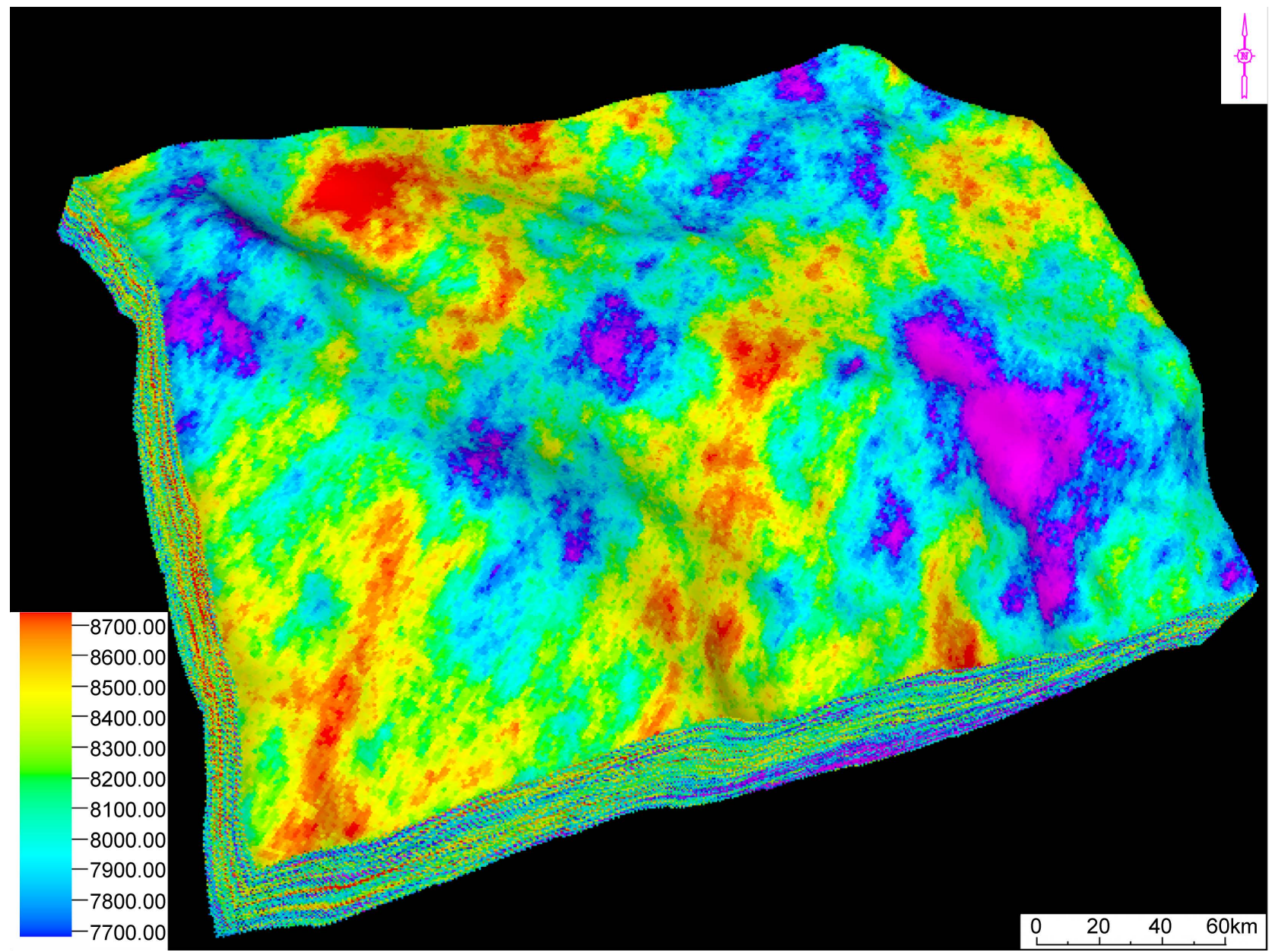

Figure 2. Wave impedance model of Dongfang area. 


\subsection{P-Wave Velocity Model}

Three general ways of obtaining P-wave velocity: pre-stack simultaneous inversion, stack velocity from seismic data processing and then calculate longitudinal wave velocity through DIX formula, by using other seismic attributes with better correlation. Pre-stack simultaneous inversion method is not applicable in this area because of all from post-stack data. In this study, we use two methods to establish P-wave velocity model: One is obtained by DIX formula, which input discrete point of velocity, then sampled in the geological model and interpolated to form a layer velocity model [12] [13] [14] [15] [16]. Through this method, the difference between processing velocity and Sonic calculation velocity is obvious. Another method is to establish the velocity model by using relationships between various seismic attributes and velocity. Statistical analysis through speed and impedance data of drilled wells (Figure 3), it's easy to find that two properties have good correlation with $0.98 \mathrm{R}$-squared value, which indicates this method is feasible. So P-wave velocity model can be obtained from the above wave impedance data volume.

Compared with these two methods, we can find that it's difficult to explain partial low-speed or high-speed stratigraphy owing to taking no consideration of time-depth conversion and velocity prediction by pressure, as well as limitation of velocity resolution. Thus, changes in the processing velocity is relatively stable, in terms of velocity obtained by wave impedance can reflect high and low

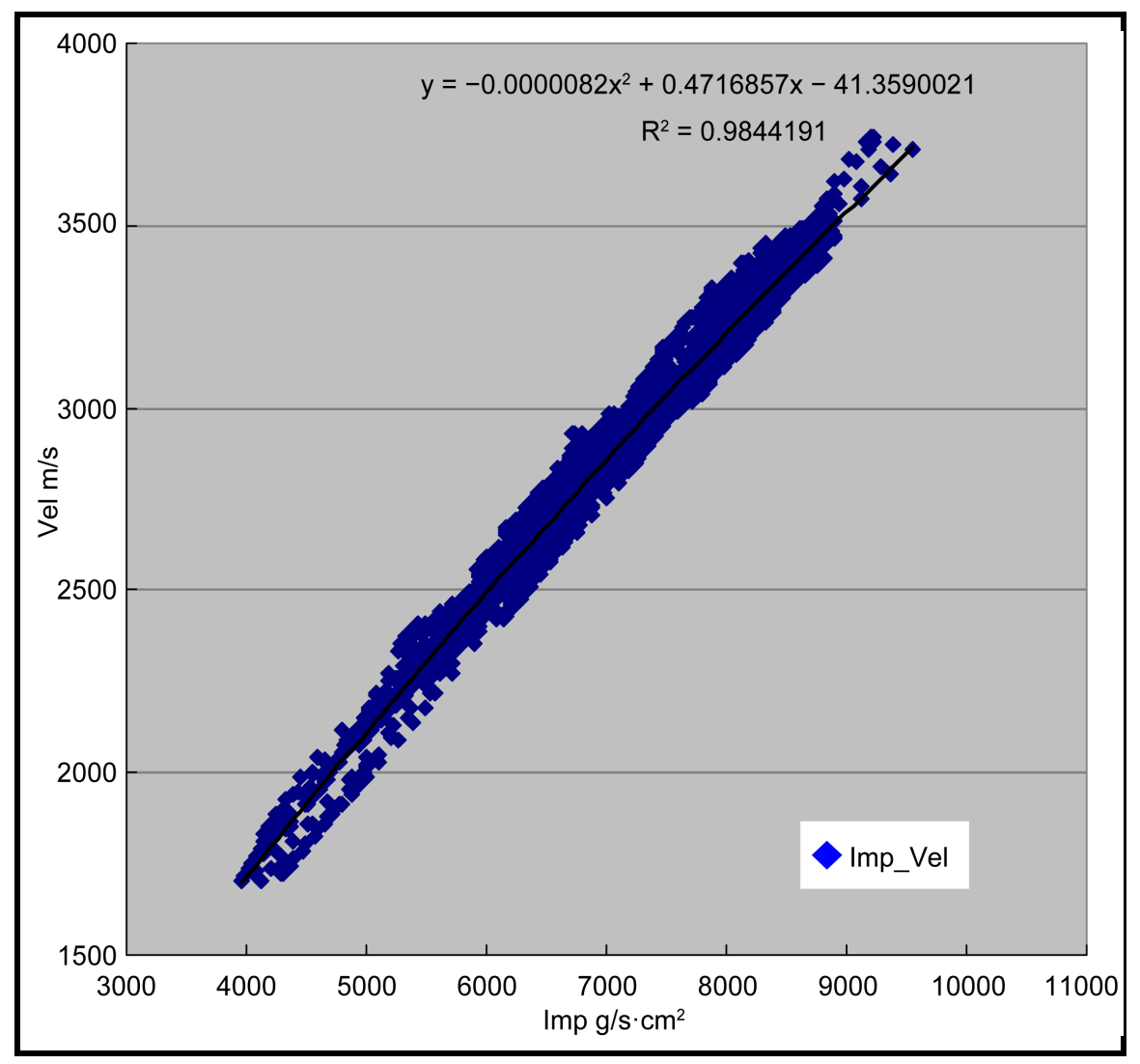

Figure 3. Crossplot analysis diagram of impedance and velocity. 


\section{Lithology Model}

Principle of lithology model is to establish lithology between wells and predict reservoir structure by using stochastic modeling method and a variety of constraints. The accuracy of lithology modeling on the one hand depends on geological accuracy, on the other hand depends on constraint conditions [17] [18] [19]. When seismic information shows good response to lithology, the establishment of the lithology model through three-dimensional seismic information will have a good effect.

From the relationship between impedance of drilled wells and lithology, the impedance of the target area can well reflect lithology. Therefore, this prediction shows high accuracy. From the point of well logging and integrated lithology interpretation, lithology can be classified as two types (sandstone and mudstone) in order to make better use of impedance data. Specific procedure of the actual modeling process is as follows:

1) Roughen lithology of four drilled wells according to model grid in target area;

2) Sandstone content contour map can be made based on geo-statistical analysis of lithology, vertical ratio and variogram. It can serve as trend constraint of lithology model;

3) Statistical correspondence analysis between impedance characteristics and different lithology can be spatial constraints of lithology model;

4) Under the above constrained conditions, establish multiple lithology models by stochastic simulation algorithm and optimize model based on geological knowledge.

Establish lithology model of Dongfang district by the constraint of longitudinal, plane and three dimensional phase (Figure 4).

\section{Three-Dimensional Pore Pressure Model}

Four pore pressure models are established in this study. Pore pressure prediction model is set up by using velocity and seismic information in less well areas, while for relatively more wells areas pressure coefficient of drilled wells are more
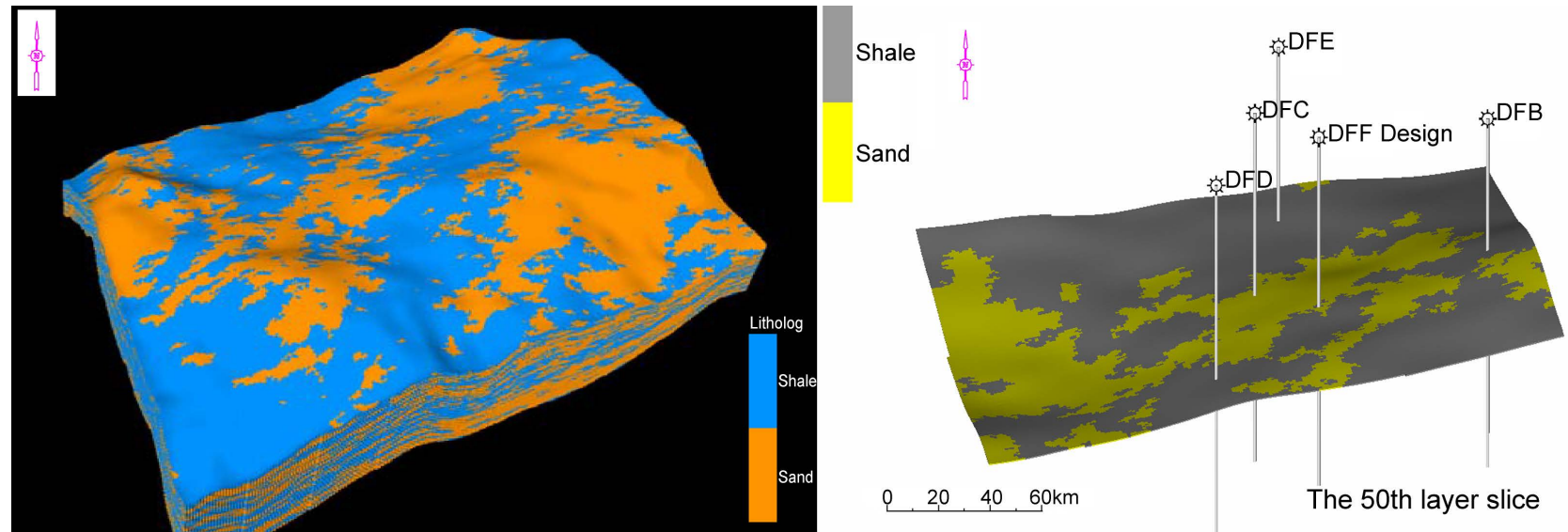

Figure 4. Lithology model and bedding slices. 
commonly used. Four models can be used to predict the formation pore pressure.

\subsection{Pore Pressure Prediction Model}

Combined with acoustic travel time curves and MTD data, pore pressure prediction model is summarized to represent the relationship between P-wave velocity difference and pressure coefficient [20] [21]. During seismic attribute modeling process, two models based on seismic processing velocity and $\mathrm{P}$-wave velocity(interval velocity) are established. Combined with pressure prediction model and two velocity models, pore pressure prediction model can be obtained respectively by discriminant function.

According to the analysis of prediction error, pressure predicted by wave impedance has high accuracy with actual pressure [22] [23] [24] [25] [26]. The consideration of seismic data imaging, restriction of velocity resolution as well as partial low-speed or high-speed stratigraphy lead to pressure anomaly is difficult to get. Pore pressure by processing velocity can reflect overall vertical pressure trends. The pore pressure from impedance conversion can closely reflect the pressure characteristics. Therefore, comprehensive analysis shows that accuracy of pore pressure is much higher by wave impedance model. Pressure prediction model is recommended to use impedance conversion velocity model (Figure 5).
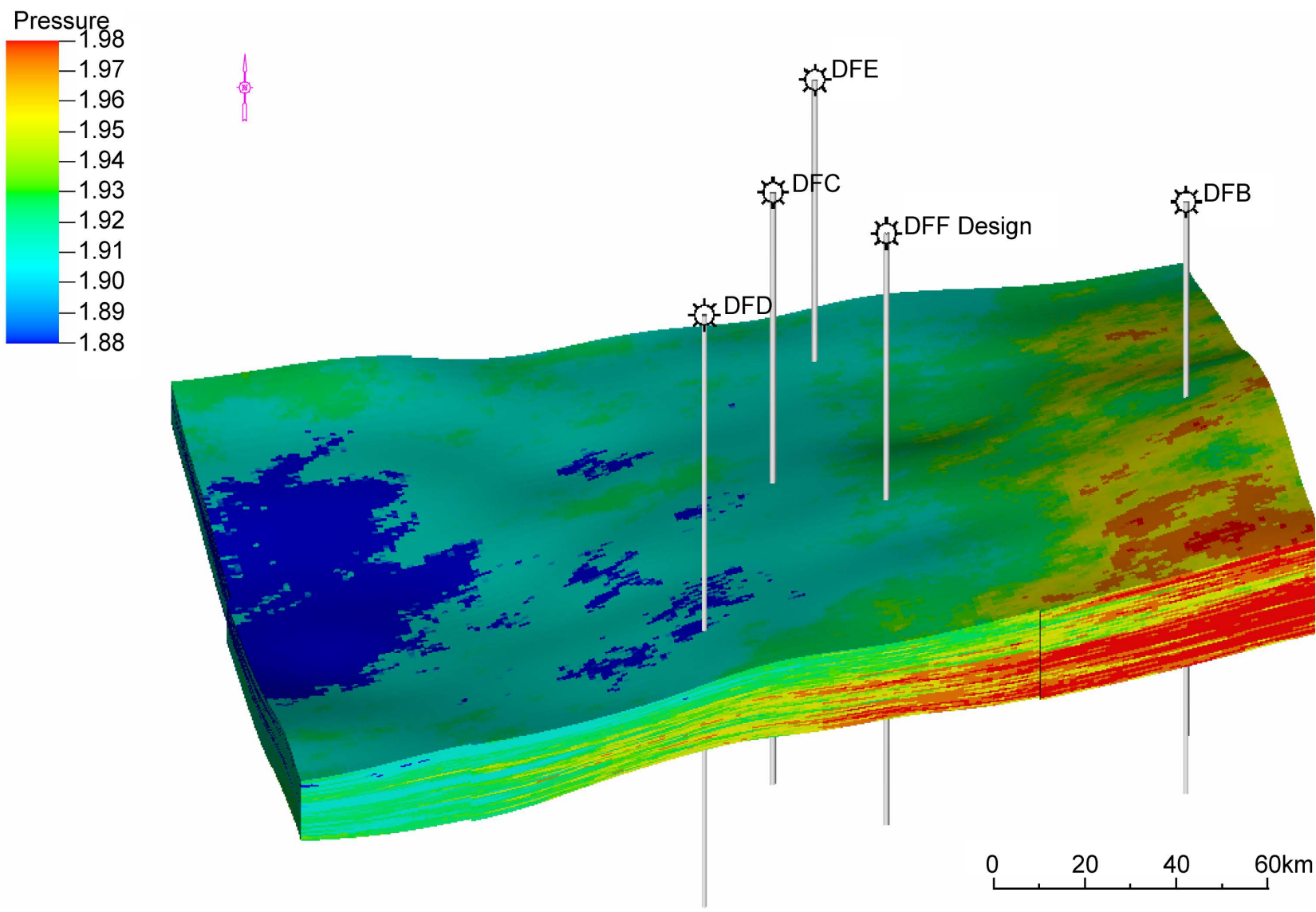

Figure 5. Pressure prediction model of Huangliu formation. 


\subsection{Solid Model of Pore Pressure}

Different from pore pressure prediction models, solid model of pore pressure is obtained from interpolated trend control. Based on pressure coefficient of a single well, solid model of pore pressure is updated from time to time by newly drilled wells with seismic attributes as lateral trends. For Dongfang district, solid model of pore pressure is applied to data of good quality, more accurate velocity, pressure coefficient and interval velocity associated with good relativity.

Figure 6(a) and Figure 6(b) are contour maps of reservoir and cap pressure coefficient through pressure prediction model constraints, among which 6(a) is contour maps of reservoir pressure coefficient, 6(b) is contour map of cap pressure coefficient. As can be seen from the figures, the reservoir pressure coefficient is concentrated from 1.91 to 1.93 , the average is about 1.93, partial pressure of the pressure coefficient is 1.94 . Changes of cap pressure coefficient are relatively large, concentrated from 1.7 to 1.8 , the average is 1.78 , partial pressure of is 1.81 , which can reflect the cap sealing capacity. Meanwhile different pressure coefficients and structures of reservoir and cap have different requirements of specific gravity of slurry.

\section{Conclusions}

1) Three-dimensional structural model, phase model, wave impedance model are the basis of velocity model and lithology model. Velocity model can be used to establish depth conversion and pressure prediction model. Lithology model based on longitudinal, plane and wave impedance constrained trends. Threedimensional stress field model is established by regional stress analysis.

2) Pore pressure model is divided into pore pressure prediction model and pore pressure solid model, among which pore pressure prediction model has good predictive capabilities of formation pore pressure; pore pressure solid
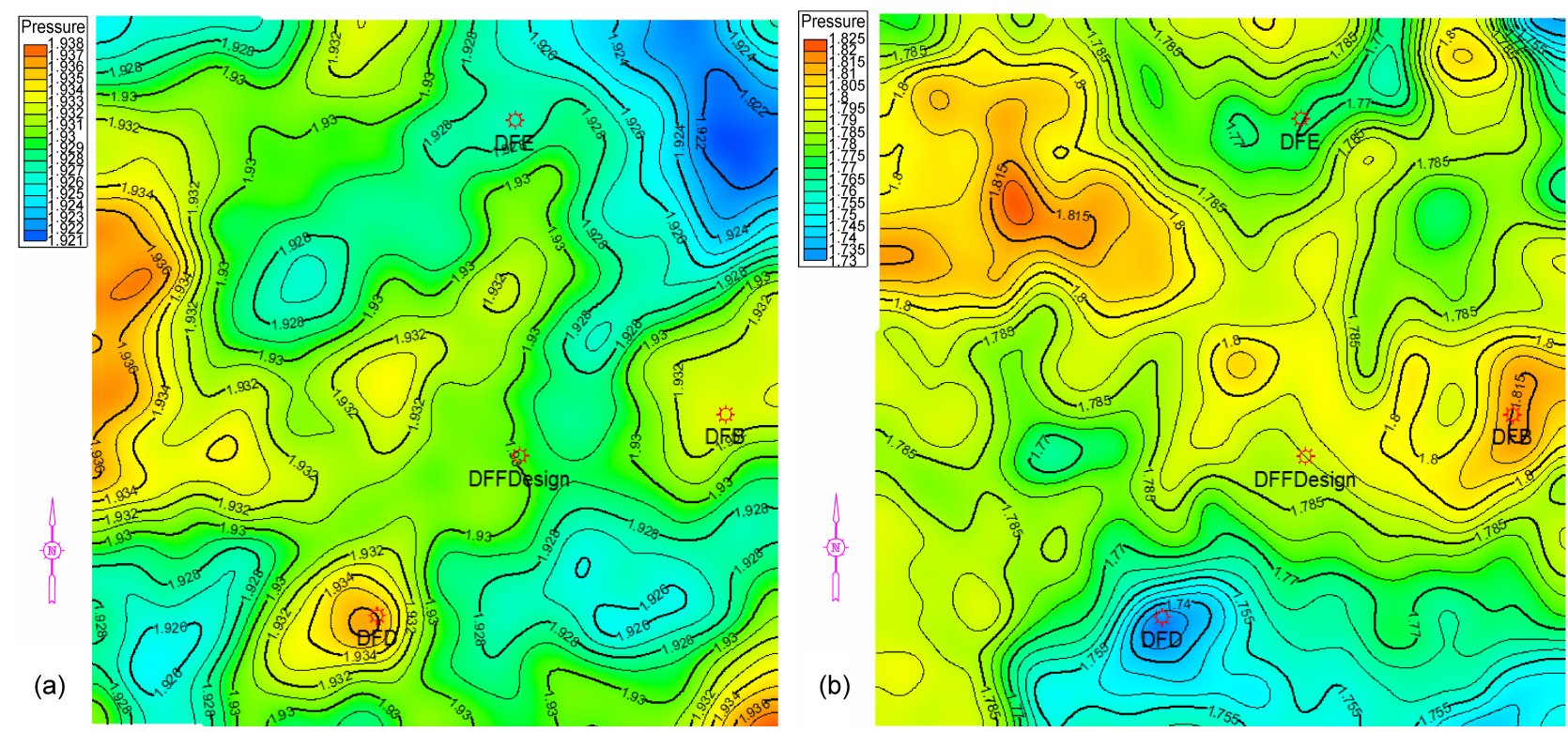

Figure 6. Contour map of reservoir and cap pressure coefficient in Huangliu formation. 
model is much closer to the true formation pore pressure with constantly updated data.

In conclusion, more accurate forecast pore pressure before drilling can not only guide well construction design, but also greatly improve drilling safety and save drilling costs.

\section{References}

[1] Xie, Y.-H., Wang, Z.-F. and Li, X.-S. (2005) Concealed Gas Reservoirs and Favorable Target Evaluation in Ying-Qiong Basin. Internal Report, Zhanjiang Branch of CNOOC Ltd.

[2] Wang, Z.-F. and Luo, X.-R. (2004) Drilling Pressure Monitoring Technology of High Temperature and High Pressure Strata in Ying-Qiong Basin. Petroleum Industry Press, Beijing.

[3] Yang, J.-H. and Hu, Z.-L. (2000) Natural Gas Accumulation Conditions of OverPressure Strata in Ying-Qiong Basin. Internal Report, Zhanjiang Branch of CNOOC Ltd.

[4] Wu, S.-H., Jin, Z.-K. and Huang, C.-D. (1999) Reservoir Modeling. Petroleum Industry Press, Beijing.

[5] Zhang, Y.-W. and Xiong, Q.-H. (1997) Terrestrial Reservoir Description. Petroleum Industry Press, Beijing.

[6] Zhang, T.-F. and Wang, J.-H. (1995) Stochastic Simulation of Gas Reservoir in Geological Application. In: Mathematical Geology in China Vol. 6, Geological Publishing House, Beijing, 62-73.

[7] Ran, J.-B., Li, J.-X. and Liu, Y.-C. (2004) Reservoir Description Techniques and Methods Based on Three-Dimensional Seismic Data. Oil Geophysical Prospecting, No. 1.

[8] Yang, Z.-W., Xie, Y.-N. and Tang, J.-M. (2000) Multi-Well Constrained Seismic Inversion Technique Strata Tight Sandstone Gas Reservoirs in Western Sichuan Description. Geophysical and Geochemical Exploration, 22, 90.

[9] Chen, H.-Q. and Zhu, X.-M. (2008) Fine Reservoir Description of Progress in Modeling of Sedimentary Facies. Geological Information, No. 2.

[10] Lv, X.-G., Ma, F.-S. and Tian, D.-H. (1994) Lithology, Physical Properties and Distribution of Interlayer. Petroleum Exploration and Development, No. 5.

[11] Wei, J. (2007) Geological Modeling Technology. Progress in Exploration Geophysics, 30, 1-6.

[12] Wei, J., Tang, J. and Yue, C.-Q. (2008) Three-Dimensional Geological Modeling Technology. Geophysical Prospecting for Petroleum, 47, 319-327.

[13] Pan, X., Li, J.-H. and Zhou, L.-F. (2008) Group of Complex Fault Block Reservoir Structure Modeling and Its Application. Block Oil and Gas Field, 15, 53-58.

[14] Ding, K.-X. (2008) Fine Structural Complex Fault Block Oil Reservoir Modeling Technology-A Case Study of Fu Lin Oil field. Oil and Gas Technology, 30, 247250.

[15] Yong, Q., Dai, K.-M. and Chen, S.-W. (2002) Three-Dimensional Geological Modeling of Sandy Braided Reservoir. Petroleum Geology \& Oilfield Development in Daqing, 21, 34-36.

[16] Zou, X.-X. and Wu, Y.-H. (2009) Complex Fault Block Oil Reservoir Remaining Oil Distribution and Tapping the Potential. Chongqing Institute of Technology (Natu- 
ral Science), 11, 12-15.

[17] Chen, L.-Y. (2001) Complex Fault Block Reservoir Description and Reservoir Distribution of Remaining Oil. Southwest Petroleum Institute, Nanchong.

[18] Wang, L.-J. and Sun, Y.-F. (2006) Complex Fault Block Oil Reservoir and Prediction of Remaining Oil Distribution. Xinjiang Oil and Gas, 2, 47-53.

[19] Liu, Z.-F., Hao, T.-Y. and Yang, C.-C. (2003) The Sedimentary Model and Reservoir Stochastic Model. Progress in Geophysics, 18, 519-523.

[20] Zhang, S.-L. and Xia, B. (2007) Overview of Modeling Complicated Geological Structure. Progress in Geophysics, 6, 1900-1903.

[21] Liu, A.-Q., Chen, D.-Y. and Ou, Z.-N. (2012) Lithology Modeling in South of Yanan District in Qiongdongnan Basin. Progress in Geophysics, 27, 634-641.

[22] Luo, S.-Y. (2014) Study on the Overpressure Characteristic and Hydrocarbon Accumulation in Bonan Depression of Zhanhua Subbasin. China University of Geoscience, Wuhan, 60-84.

[23] Lv, H.-D. (2014) Prediction Model of Surge Pressure at High Temperature and High Pressure. Northeast Petroleum University, Heilongjiang, 40-43.

[24] Guo, Y., Wang, H. and Li, K. (2016) Research on Three Pressure Models in West Sichuan Xujiahe Formation. Petrochemical Industry Application, 35, 80-83.

[25] Li, Q. (2015) The Prediction and Application of Formation Pressure in Shahejie Group of Shen 257 Block of Liaohe Oil Field. Northeast Petroleum University, Heilongjiang, 16-34.

[26] Peng, C., Dai, J. and Yang, S. (2013) Seismic Guided Drilling: Near Real Time 3D Updating of Subsurface Images and Pore Pressure Model. 6th International Petroleum Technology Conference, Beijing, 26-28 March 2013, 6 p. https://doi.org/10.2523/IPTC-16575-MS

\section{Scientific Research Publishing}

Submit or recommend next manuscript to SCIRP and we will provide best service for you:

Accepting pre-submission inquiries through Email, Facebook, LinkedIn, Twitter, etc. A wide selection of journals (inclusive of 9 subjects, more than 200 journals)

Providing 24-hour high-quality service

User-friendly online submission system

Fair and swift peer-review system

Efficient typesetting and proofreading procedure

Display of the result of downloads and visits, as well as the number of cited articles

Maximum dissemination of your research work

Submit your manuscript at: http://papersubmission.scirp.org/

Or contact ojms@scirp.org 